\title{
Invasieve pijnbehandeling : het uur van de waarheid
}

\author{
Citation for published version (APA):
}

Sluijter, M. E. (1993). Invasieve pijnbehandeling : het uur van de waarheid. Datawyse / Universitaire Pers Maastricht. https://doi.org/10.26481/spe.19930423ms

Document status and date:

Published: 23/04/1993

DOI:

10.26481/spe.19930423ms

Document Version:

Publisher's PDF, also known as Version of record

\section{Please check the document version of this publication:}

- A submitted manuscript is the version of the article upon submission and before peer-review. There can be important differences between the submitted version and the official published version of record.

People interested in the research are advised to contact the author for the final version of the publication, or visit the DOI to the publisher's website.

- The final author version and the galley proof are versions of the publication after peer review.

- The final published version features the final layout of the paper including the volume, issue and page numbers.

Link to publication

\footnotetext{
General rights rights.

- You may freely distribute the URL identifying the publication in the public portal. please follow below link for the End User Agreement:

www.umlib.nl/taverne-license

Take down policy

If you believe that this document breaches copyright please contact us at:

repository@maastrichtuniversity.nl

providing details and we will investigate your claim.
}

Copyright and moral rights for the publications made accessible in the public portal are retained by the authors and/or other copyright owners and it is a condition of accessing publications that users recognise and abide by the legal requirements associated with these

- Users may download and print one copy of any publication from the public portal for the purpose of private study or research.

- You may not further distribute the material or use it for any profit-making activity or commercial gain

If the publication is distributed under the terms of Article $25 \mathrm{fa}$ of the Dutch Copyright Act, indicated by the "Taverne" license above, 
Universiteitsbibliotheek

R॥|ksuniversıtelt Lımburg

Postbus 616

6200 MD Maasiticht

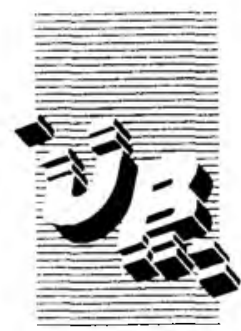

De uitleentermijn verstrijkt op

\section{JWint 9993 \\ $15 \mathrm{mLL} 193$ \\ 23 OKT. 2001}

Gelieve deze publıcatie tijdig te retourneren of (telefonisch) verlenging van de uilleentermijn aan te vragen. 


\section{INVASIEVE PIJNBEHANDELING}

\section{Het uur van de waarheid}

Rede uitgesproken bij de aanvaarding van het ambt van

hoogleraar in de invasieve pijnbestrijdingstechnieken aan de Rijksuniversiteit Limburg op Vrijdag 23 April 1993

door

DR.M.E.SLUIJTER

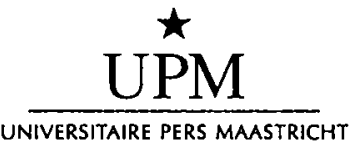




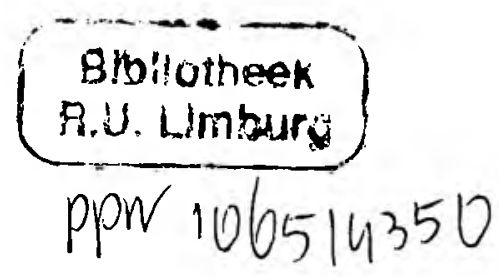

ISBN 9052780781

DATAWYSE | Universitaire Pers Maastricht 
Mijnheer de Rector Magnificus, dames en heren hoogleraren, waarde collegae, dames en heren studenten en gij allen die deze plechtigheid met Uw aanwezigheid vereert;

Het is vandaag een historische dag. Historisch, niet omdat ik hier sta om mijn ambt te aanvaarden. Maar historisch vanwege mijn leeropdracht. Invasieve methoden ter behandeling van chronische pijn zijn een omstreden onderwerp. Het stemt tot dankbaarheid en tevredenheid dat middels deze leerstoel deze methoden de aandacht krijgen, die ze verdienen. Ik zal $U$ het komende uur trachten duidelijk te maken waarom invasieve methoden aanleiding zijn tot discussie, welke daarbij gebezigde argumenten terecht zijn en welke niet en tenslotte welke lering wij hieruit kunnen trekken voor een verantwoord beleid in de toekomst.

Chronische pijn is in de allereerste plaats een probleem voor degeen die de pijn ervaart. De Libanese dichter en philosoof KAHLIL GIBRAN (1923) omschreef pijn als "the breaking of the shell that encloses your understanding". Hij brengt daarmee treffend de ontreddering tot uitdrukking, die chronische pijn teweeg kan brengen.

Maar niet alleen voor het slachtoffer is chronische pijn een probleem. Daar is ook ons hele sociaal-maatschappelijke bestel. Chronische pijn - en dan met name de chronische pijn die uitgaat van ons bewegingsapparaat - is de belangrijkste oorzaak voor ziekteverzuim en arbeidsongeschiktheid, op afstand gevolgd door cardiovasculaire aandoeningen. De financiële gevolgen van medische consumptie, ziekteverzuim en arbeidsongeschiktheid tezamen belopen in ons land verschillende miljarden guldens per jaar.

Voor een goed begrip van wat volgt wil ik nu eerst kort met $U$ ingaan op het mechanisme van chronische pijn. In het verleden 
heeft de geneeskunde pijn traditioneel beschouwd als het gevolg van een overmaat van zenuwprikkels, afkomstig van een pijn veroorzakend focus. Deze stelling is niet houdbaar. Nieuwere neurophysiologische inzichten danken wij aan het baanbrekende werk van onze landgenoot NOORDENBOS (1959) en aan de door MELZACK en WALL in 1964 gelanceerde poortheorie.

In grote lijnen kan men stellen dat de informatie vanuit de periferie het centrale zenuwstelsel via twee zenuwvezelsystemen bereikt. Er is een snel geleidend systeem van dikke, gemyeliniseerde zenuwvezels en ex is een langzaam geleidend dunvezelig systeem. De poorttheorie verkondigt nu dat de prikkelbaarheid van de zenuwcellen in de dorsale hoorn van het ruggemerg afneemt onder invloed van via het snelle systeem binnenkomende prikkels. Deze "snelle informatie" sluit derhalve de poort. Omgekeerd neemt de prikkelbaarheid toe onder invloed van langzame informatie.

Maar dat is niet alles. De prikkelbaarheid van de achterhoorncellen staat ook sterk onder invloed van de activiteit van z.g. afdalende banen. Deze afdalende banen verbinden de hogere hersencentra met de achterhoorn van het ruggemerg en vormen de schakel tussen psychologische processen en de prikkelbaarheid van de achterhoorncellen. $Z_{i j}$ zijn er bijvoorbeeld voor verantwoordelijk als acute pijn door een sterke psychische prikkel "niet gevoeld wordt".

Aldus werd een verbinding gelegd tussen neurophysiologie en psychologie. Pijn is een subjectieve ervaring, iedere vorm van pijn, of deze nu acuut of chronisch is, heeft een psychologisch equivalent. De poortheorie maakt nu aannemelijk dat de binnenkomende informatie al op ruggemergsniveau door psychologische invloeden wordt gemoduleerd. 
Men kan nu in het algemeen vier soorten pijn onderscheiden. In de eerste plaats is er die vorm van chronische pijn, waarbij er een voortdurende stroom van informatie aanwezig blijft vanuit een pijn veroorzakend focus. We spreken dan van nociceptieve pijn. Denkt U aan de carcinoompatient of aan de pijn die veroorzaakt wordt door een door osteoporose ingezakte wervel.

In de tweede plaats is er deafferentatiepijn. Bij deze vorm van pijn is er te weinig snelle informatie om de poort te sluiten. Deze toestand kan het gevolg zijn van doorsnijding van een zenuw of van ziekten die de zenuwfunctie aantasten zoals een postherpetische neuralgie of een polyneuritis diabetica.

Het derde type pijn noemen we centrale pijn en is het gevolg van processen binnen het centrale zenuwstelsel. Zo kan pijn blijven bestaan na een doorgemaakte hersenbloeding.

En tenslotte is er de pijn waarbij er in feite somatisch niets aan de hand is. Deze vorm van pijn begint vrijwel steeds als nociceptieve pijn. De daarbij optredende psychische factoren hebben daarbij echter zozeer de overhand gekregen dat de pijnsensatie in stand blijft ondanks het wegvallen van het nociceptieve focus. Men spreekt van het chronisch benigne pijnsyndroom.

De diagnostiek nu is eenvoudig voorzover het de denervatiepijn en de centrale pijn betreft. Veel moeilijker ligt het onderscheid tussen nociceptieve pijn en het chronisch benigne pijnsyndroom omdat mengvormen van deze soorten pijn eerder regel dan uitzondering zijn. Eerst wil ik mij met $U$ richten op de behandeling van nociceptieve pijn.

Zoals gezegd heeft de geneeskunde pijn traditioneel beschouwd als het gevolg van nociceptie. In dat licht bezien is het niet verwonderlijk, dat er in het verleden vele pogingen zijn onder- 
nomen om pijn weg te nemen door doorsnijding van de zenuwbanen, die deze prikkels geleiden. Zo werd de chirurgische doorsnijding van uit het ruggemerg uittredende zenuwwortels reeds rond de eeuwwisseling toegepast en beschreef KIRSCHNER in 1931 de electrocoagulatie van het ganglion van Gasser ter behandeling van de trigeminusneuralgie. Het resultaat was steeds teleurstellend omdat de patient deafferentatiepijn kreeg in plaats van zijn oorspronkelijke kwaal.

Desalniettemin werden de pogingen voortgezet. Tot 1960 bleef pijn synoniem met nociceptief focus. Inmiddels kwam ook de herniachirurgie tot ontwikkeling en ontwikkelde zich een waarlijk navelstaren op kleine morphologische afwijkingen om dat nociceptieve focus op te sporen. Met name in de Verenigde Staten wisten neurochirurgen en orthopaeden van wanten. Op een van mijn reizen in dat land heb ik een patient mogen aanschouwen die $33 x$ aan zijn rug was geopereerd.

De kentering kwam in de zestiger jaren toen de poortheorie werd gelanceerd en toen de stem van de anesthesioloog BONICA begon door te klinken, die de behandeling van chronische pijnpatienten in handen wilde leggen van een multidisciplinair team in plaats van bij een solitair werkende specialist. Gezien de uit de hand gelopen situatie was daar dan ook alle reden toe.

Juist in deze periode van bezinning op invasieve ingrepen werden de radiofrequente laesies ontwikkeld. Bij een dergelijke laesie wordt in een discreet gebied om de punt van een electrode heen warmte opgewekt door middel van radiofrequente stroom. De methode werd in ruwe en ongecontroleerde vorm al gebruikt door KIRSCHNER in 1931. De verfijning in techniek werd ingegeven door de ontwikkeling van de percutane chord otomie. Andere toepassingen waren anathema totdat SWEET in 1974 een 
wezenlijk nieuw element inbracht. SWEET beschreef in feite een gemodificeerde versie van de techniek van KIRSCHNER waarbij hij suggereerde dat het mogelijk was de toediening van de radiofrequente stroom door temperatuurmeting in de top van de electrode zodanig te sturen dat er uiteindelijk een selectieve onderbreking van zenuwgeleiding ontstond, waarbij het gemyeliniseerde systeem minder werd getroffen dan het dunvezelige systeem. Zo zou het mogelijk zijn nociceptieve prikkels in aantal te reduceren zonder daarbij de poort te openen. Ook het experimentele werk van LETCHER en GOLDRING (1969) wees in deze richting.

De methode van SWEET is inmiddels algemeen geaccepteerd. Anders verging het pogingen van andere Amerikaanse neurochirurgen om dit principe ook voor spinale pijn te introduceren. UEMATSU (1974) beschreef de selectieve laesie van het dorsale ganglion van segmentale zenuwen en SHEALY (1975) de denervatie van de facetgewrichten door middel van radiofrequente laesies. Beide methoden kwamen destijds niet van de grond, ach teraf bezien door een mengsel van verkeerde indicatiestelling en door het gebruik van een electrode van groteske afmeting.

De grondgedachte bleef evenwel naklinken en het zijn met name Nederlandse anesthesiologen geweest die in de 70er jaren dit neurochirurgische koekoeksei hebben uitgebroed. Dat is geen gemakkelijke opgave geweest. Ter linker zijde waren er de psychologen die riepen dat er geen nociceptie was, ter rechterzijde de neurochirurgen die zelf ook geen oplossing wisten maar zeker geen bemoeienis van vreemden met hun orgaansysteem duldden. Daar kwam nog bij dat de beschikbare apparatuur uiterst gebrekkig was. 
De grote doorbraak van radiofrequente laesies begon in feite in 1980 bij de introductie van het moderne dunne, 22G electrodesysteem. Niet alleen heeft dit bijgedragen tot de veiligheid van de methode, ook werd het mogelijk het aantal radiofrequente technieken aanzienlijk uit te breiden en werden de ingrepen veel minder belastend voor de patient.

Welke is dan thans de positie van radiofrequente laesies? We zullen hierbij drie vragen hebben te beantwoorden:

- Wat zijn de grondprincipes van radiofrequente laesies?

- Zijn radiofrequente laesies veilig?

- Zijn radiofrequente laesies zinvol?

De grondprincipes zijn de volgende:

1. Een radiofrequente laesie beoogt een reductie in het aantal nociceptieve prikkels zonder daarbij de poortfunctie van het dikvezelige systeem an te tasten.

2. Bij een radiofrequente laesie dienen de efferente functies van de zenuw gespaard te blijven.

De reductie van het aantal nociceptieve prikkels kan op twee manieren worden bereikt:

- er wordt een onderbreking gemaakt in een sensibele structuur, die geen huidinnervatie verzorgt. Dit principe geldt voor de percutane facetdenervatie en voor laesies in de sympathische grensstreng;

- er wordt een partiele, selectieve onderbreking gemaakt waar het gaat om sensibele structuren van grotere omvang zoals het dorsale ganglion van segmentale zenuwen. Deze selectieve onderbreking wordt verkregen door de electrode doelbewust buiten de te behandelen structuur te plaatsen. Deze structuur wordt zodoende slechts blootgesteld aan de temperaturen in 
de periferie van de laesie. Dit is juist het temperatuurtraject waarin verwacht kan worden dat de ongemyeliniseerde, dunne vezels selectief onderbroken worden.

De wetenschappelijke onderbouwing van dit principe begint thans gestalte te krijgen. Onlangs publiceerden VAN KLEEF, SPAANS en medeauteurs (1993) vanuit deze universiteit het resultaat van een onderzoek waarbij werd aangetoond dat de functie van gemyeliniseerde vezels na een selectieve rhizotomie in het halsgebied inderdaad gespaard blijft. Rest nog de vraag, of de functie van niet-gemyeliniseerde vezels inderdaad wel wordt aangetast. Het onderzoek hiernaar is in volle gang.

Het is betreurenswaardig dat dit grondprincipe van radiofrequente laesies nog steeds bij veel medici onbekend is. Het grote obstakel hierbij is de terminologie. Alle sussende adjectiva ten spijt doet het woord "rhizotomie" nog steeds het ergste vermoeden. Het ware beter te spreken van een Segmental Thermal Input Modulation (STIM).

Wat betreft de veiligheid moet onderscheid gemaakt worden tussen complicaties die het gevolg zijn van de ingreep als zodanig en complicaties die veroorzaakt worden doordat de ingreep met een verkeerde techniek of op verkeerde indicatie is geschied. Het aantal complicaties door de methode als zodanig is uitermate gering. Ik neem als voorbeeld de selectieve rhizotomie in het halsgebied. Deze ingreep wordt naar schatting in Nederland 5000x per jaar uitgevoerd en dit is al gedurende tenminste vijf jaar het geval. Er zijn mij uit deze periode na telefonisch navragen bij collegae 2 complicaties op termijn ter ore gekomen. 
Zijn radiofrequente laesies zinvol? Hierbij moeten we onderscheid maken tussen twee groepen laesies. Enerzijds zijn er die behandelingen waarbij de patient bij welslagen van de ingreep door een enkele laesie geheel pijnvrij wordt. Een patient doopte deze gang van zaken tot het "Lourdes-effect". Voorbeelden zijn de percutane chordotomie bij enkelzijdige carcinoompijn, de laesie volgens SWEET bij de trigeminusneuralgie en de laesie van het ganglion sphenopalatinum bij cluster hoofdpijn. Bij deze ingrepen is de doelmatigheid niet in het geding.

Ik zal de discussie dan ook beperken tot de toepassing van radiofrequente laesies bij spinale pijn. Het gaat hierbij met name om die patienten, bij wie bij onderzoek geen tastbare afwijkingen worden gevonden zoals een hernia nuclei pulposi of een vernauwing van het wervelkanaal. Bij deze groep patienten doet zich een moeilijkheid voor. De wervelkolom is een complexe structuur, waarbij pijn van verschillende elementen van die structuur ofwel van combinaties daarvan kan uitgaan. Daarbij komt dat nociceptie met name uitgaande van de uncovertebrale gewrichten en van de annulus fibrosus zich onttrekken aan onze diagnostiek. Een arthrotisch facetgewricht en een discuslaesie hoeven niet per se pijnlijk te zijn, een normaal gewricht en een ogenschijnlijk normale discus kunnen dat wel zijn.

De behandeling bestaat dan ook veelal uit een reeks diagnostische blokkades met een plaatselijk verdovingsmiddel, gevolgd door een radiofrequente laesie. Dikwijls ook moeten laesies op meerdere plaatsen worden aangebracht, alvorens resultaat wordt geboekt. Dit resultaat is dan bovendien dikwijls nog partieel, in tegenstelling tot het bovengenoemde Lourdes-effect. Dit bemoeilijkt de beoordeling van het resultaat van iedere laesie afzonderlijk. 
Het is dan ook niet verwonderlijk, dat op dit arbeidsterrein nog veel werk verzet moet worden. Bovendien waren er nog andere ongunstige factoren in het spel. Het werk op dit terrein werd tot voor kort vrijwel uitsluitend door perifeer werkende anesthesiologen verricht, die weinig tijd konden vrijmaken voor klinisch wetenschappelijk onderzoek. Voorts ontbreekt het in deze groep patienten aan een nomenclatuur van pijnsyndromen met vaste criteria. Men hanteert beschrijvende termen als cervicaal syndroom of lumbago, in feite als teken van onvermogen. De indeling van de IASP is voor degeen die met radiofrequente laesies werkt moeilijk bruikbaar. Slechts voor hoofdpijn is er de classificatie van de International Headache Society, ook deze behoeft nadere precisering.

Wat is er dan wel bekend? Een totale behandeling met radiofrequente laesies is succesvol bij een groot aantal patienten. Gezien het ontbreken van gestructureerd prospectief onderzoek moeten weliswaar vraagtekens geplaatst worden bij de omvang van dit succes, maar anderzijds lijkt de kans op een placebo effect bij deze behandelingen op voorhand klein. Het gaat hier immers om patienten die allen reeds jaren lang klachten hebben en die op het terrein van suggestieve behandelingen gepokt en gemazeld zijn. Bovendien is een onmiddellijk en compleet effect van de radiofrequente laesie uitzondering. Dikwijls volgt eerst een periode met napijn, ofwel succes volgt pas na de tweede of derde behandeling.

$\mathrm{Na}$ een succesvolle behandeling kan de pijn recidiveren. Gezien de wijze, waarop radiofrequente laesies worden toegepast, is dat ook niet verwonderlijk. De pijnvrije periode kan varieren van enkele maanden tot meer dan tien jaar. In principe moet een radiofrequente laesie echter gezien worden als niet meer dan een methode, die een patient mogelijk voor langere duur pijnvrij kan 
maken. Deze periode kan dan dikwijls benut te worden om conservatieve methoden een betere kans van slagen te geven. Anderzijds mist de term "recidief" hier de wat omineuze bijklank zoals dat bijvoorbeeld het geval is na chirurgische ingrepen. Een herhaling van de behandeling met radiofrequente laesies heeft als regel een gelijke kans op succes.

Samenvattend kan worden gesteld dat radiofrequente laesies een hoge mate van veiligheid bezitten, mits ze lege artis en op goede indicatie worden uitgevoerd. Bij de behandeling van enkele aandoeningen hebben ze zich een vaste plaats verworven. $\mathrm{Bij}$ de behandeling van spinale pijn lijken de resultaten gunstig maar moet een voorbehoud gemaakt worden in afwachting van de uitkomsten van te verrichten prospectief onderzoek.

Veel valt of staat bij de vraag of er bij patienten met langdurige spinale pijn al of niet nog sprake is van relevante nociceptie. Het antwoord op deze vraag is waarschijnlijk per patient verschillend en het hangt bovendien af van de optiek van de behandelaar. Voor beide mogelijke antwoorden zijn valide argumenten aan te dragen. Afwezigheid of irrelevantie van nociceptie wordt gebaseerd op de dikwijls negatieve uitkomsten van diagnostische onderzoekingen en op de resultaten van psychologische behandelmethoden. Aanhangers van nociceptie menen dat de gebruikelijke diagnostische methoden een nociceptief focus niet kunnen uitsluiten en voeren aan dat invasieve behandelingen bij een aantal van deze patienten een uitstekend resultaat hebben.

Verder is het nog zo dat relevante nociceptie niet synoniem is met behandelbare nociceptie en dat de mogelijkheden op dit terrein mogelijk nog verder moeten worden uitgediept. Ik beschrijf $U$ als voorbeeld een methode, die thans op onze afdeling in ontwikkeling is. Bij een deel van de patienten met chronische 
rugpijn zonder uitstraling gaat pijn uit van de ring, die de tussenwervelschijf omgeeft, de z.g. annulus fibrosus. BOGDUK (1981) toonde aan, dat deze ring rijkelijk is voorzien van zenuwuiteinden. De complexe innervatie van de annulus maakte echter dat het slechts mogelijk was deze zenuwvoorziening zeer gedeeltelijk te onderbreken.

Thans hebben wij een aantal van deze patienten behandeld door een radiofrequente laesie aan te brengen in het centrum van de tussenwervelschijf. Hierbij wordt gebruik gemaakt van de wetenschap dat de grootte van een radiofrequente laesie bepaald wordt door de centrale temperatuur enerzijds en door het "wegvangen" van warmte in het omgevende weefsel anderzijds. Omdat de tussenwervelschijf een avasculaire structuur is word $t$ er nauwelijks warmte weggevangen en wordt de laesie van een zodanige omvang dat ook bij de annulus fibrosus een temperatuurstijging van 5 tot 7 graden optreedt.

De methode is tot dusverre vrij van complicaties en de resultaten zijn uitstekend mits tevoren het juiste niveau is vastgesteld door middel van een testinjectie met lokaal verdovingsmiddel in de discus. Bij het vaststellen van de optimale parameters van de laesie is nader onderzoek gaande naar de physische eigenschappen van de discus. Er doet zich hier de bijzondere combinatie voor van een uitzonderlijk lage impedantie in een avasculaire structuur. Een ontwikkeld computermodel is van grote waarde gebleken om inzicht te krijgen in de temperatuurgradienten en zal mogelijk te eniger tijd gebruikt kunnen worden om de parameters individueel te optimaliseren.

Als deze methode de beloftes ook op termijn waar maakt, dan is er een mogelijkheid geschapen voor patienten, die tot dusverre bij gebrek aan positieve diagnostiek zeker als niet-nociceptief 
beschouwd zouden zijn. Het is echter zeker niet mijn bedoeling om dit als argument te hanteren om het nociceptieve concept zaligmakend te verklaren. Ik meen, dat er bij het gros van de ons aangeboden patienten nog weliswaar een element van nociceptie is, maar dat het de relevantie daarvan is, die sterk individueel verschilt. Wat de behandeling betreft zou dit erop neerkomen, dat de meerderheid van de patienten gebaat is bij althans een beoordeling, of uitschakeling van nociceptie mogelijk en aangewezen is. We zullen daarbij in de toekomst moeten komen tot afgebakende, geprotocolleerde schema's die ook eindig zijn. Vervolgens zal er dan een grote groep al dan niet invasief behandelde patienten overbijven die psychologische hulp behoeven om ze te leren met hun klacht of restklacht om te gaan en ze weer te integreren in hun omgeving. Zowel het chronisch benigne pijnsyndroom als niet aantoonbare maar desalniettemin reeele en behandelbare nociceptie zijn een realiteit. Ons beleid dient een twee-sporenbeleid te zijn.

Hoe is het nu gegaan met de pijnbehandeling in Nederland? In navolging van de Verenigde Staten werden ook hier in de 70er jaren een aantal multidisciplinaire teams opgericht, voornamelijk aan de universitaire centra. Daarnaast waren er een aantal solitair werkende anesthesiologen, die zich de radiofrequente technieken hadden eigen gemaakt.

Aldus ontstond een ongewenste situatie. De multidisciplinaire teams beperkten zich als regel tot een zeer gedegen diagnostiek maar zij hadden weinig of geen ervaring met invasieve ingrepen. Er was binnen de teams ook weinig initiatief om zich deze activiteiten eigen te maken. Mogelijk was dit het gevolg van een variant van wat SCOTT PECK (1983) "fragmentation of conscience" noemt. 
Aan de andere kant waren er de solitair werkende anesthesiologen. Deze waren van huis uit niet bedreven in diagnostiek. Bovendien waren ze niet opgeleid in de invasieve technieken, omdat immers de opleidingscentra deze kennis niet in huis hadden. Velen keken de kunst af bij bevriende collegae. Daar is op zich niets op tegen maar de mate waarin dat gebeurde was geheel ter discretie van de pijnbestrijder-in-spe.

Optimaal is de situatie derhalve niet geweest maar het was toch niet alleen kommer en kwel. In de afgelopen decennia heeft Nederland zich wat betreft de behandeling met radiofrequente laesies een leidende positie in de wereld verworven. Uit letterlijk alle werelddelen komen specialisten naar ons land om zich op de hoogte te stellen en technieken over te nemen. Zelfs in de Verenigde Staten met de daar heersende enorme aansprakelijkheidsproblematiek schieten de in ons land ontwikkelde technieken nu onmiskenbaar wortel.

Ik zie met voldoening dat er de laatste jaren een kentering komt in de bestaande tegenstellingen. De radiofrequente laesies hebben hun intrede gedaan in universitaire multidisciplinaire teams, uiteraard hier in Maastricht maar ook daarbuiten. Verschillende solitair werkende anesthesiologen zoeken en vinden een samenwerkingsverband in kleinere teams.

Hoe moet nu de toekomst er uitzien? Ik wil U schetsen wat naar mijn inzicht de ontwikkelingen zouden moeten zijn op het gebied van research, van organisatie van de pijnbehandeling, van de opleiding en van de financiering. Eerst wat de research betreft. Hierin heerst een grote achterstand, welke werd ingegeven door de situatie in het verleden zoals ik $U$ die heb geschetst. Het lijkt mij dat de volgende terreinen prioriteit moeten hebben: 
- de gevolgen van radiofrequente laesies, zowel in anatomisch als in physiologisch opzicht;

- het ontwikkelen van een zinvolle nomenclatuur van de verschillende spinale pijnsyndromen en van protocollen voor behandeling;

- onderzoek naar de mogelijkheden van behandeling in een vroeger stadium van het pijnsyndroom, met daaraan gekoppeld de mogelijke effecten op een beperking van de arbeidsongeschiktheid.

Wat de organisatie betreft meen ik dat de universitaire teams in ere gehouden moeten worden voor de bijzonder gecompliceerde gevallen. Deze teams kunnen echter niet hun kennis en vaardigheid behouden zonder ook minder gecompliceerde gevallen te behandelen. Zij kunnen dat gemakkelijk doen met een kernteam, bestaande uit een neuroloog, een anesthesioloog en een psycholoog zoals dat thans in Maastricht gebeurt. Daarnaast dienen de universitaire teams alle kennis en ervaring te hebben met radiofrequente laesies en dient de psychologische behandelmogelijkheid zodanig in capaciteit te worden uitgebreid dat deze het patientenaanbod kunnen verwerken. Dat is geen geringe opgave omdat psychologische begeleiding nu eenmaal arbeidsintensief is.

Daarnaast zullen er in de periferie kleine teams gevormd moeten worden, vergelijkbaar in samenstelling met het zojuist beschreven kernteam. De ervaring heeft geleerd dat dergelijke kleine eenheden uitstekend kunnen functioneren, zo nodig met incidentele hulp van andere disciplines. Als het onderzoek naar het effect op de arbeidsgeschiktheid daartoe aanleiding geeft zouden deze teams daarvoor in aanmerking komende patienten in een vroeg stadium en met voorrang kunnen behandelen. In ieder geval dient het aantal van deze teams zodanig te worden uitge- 
breid dat er een einde komt aan de onaanvaardbaar lange wachttijden, zoals die thans regel zijn.

Huisarts en specialist dienen dan de mogelijkheid te hebben om naar een specifiek lid van deze teams te verwijzen, afhankelijk van de voorgeschiedenis en van het probleem van de patient. Niet iedere patient moet noodzakelijkerwijs door het complete team worden gezien, er is bij de behandeling van chronische pijn gelukkig ook simpel werk. Op deze manier kan een klein team slagvaardig zijn en tevens een voldoende opvangcapaciteit hebben.

De opleiding van anesthesiologen, die zich op dit terrein willen toeleggen, zal geen eenvoudige zaak worden. Er zullen formatieplaatsen moeten komen bij enkele opleidingscentra. Wat het onderwijs in de invasieve methoden betreft zal gedurende de eerste jaren de hulp van de hierin bedreven perifeer werkende anesthesiologen niet gemist kunnen worden. Dat kost tijd en derhalve binnen de huidige financiele structuur ook geld. Hierbij past een tegemoetkoming, maar anderzijds zullen de betreffende anesthesiologen zich ook van hun verantwoordelijkheid bewust moeten zijn.

Een opleiding heeft alleen zin, als ook de financiele paragraaf behoorlijk is ingevuld. Het heeft immers geen zin specialisten ten koste van veel inspanning op te leiden, als zij vervolgens niet binnen het systeem kunnen functioneren. Het gaat echter niet alleen om extra uitgaven voor de pijnbestrijding, er kan ook geld terugverdiend worden door een betere structurering. Aan de uitgavenkant staan de volgende posten:

- het honorarium van een aantal specialisten, met name anesthesiologen en klinisch psychologen; 
- budgetvoorzieningen voor de ziekenhuizen. In de geschetste constructie functioneert de anesthesioloog gelijkwaardig met de overige teamleden. Het doet in determinerende zin weinig ter zake, of men dan ook wil spreken van poortspecialist. Als deze term echter gebruikt wordt in de zin van budget-genererend specialist, dan valt of staat hiermee de toekomst van de anesthesioloog als pijnbehandelaar. Men kan niet langer van ziekenhuisdirecties verlangen het budget voor pijnbehandeling via exotische constructies bijeen te garen.

Aan de andere kant is een kostenbesparing zeker mogelijk, waarbij vooral het aantal centra gereguleerd zou moeten worden. In een recent verschenen rapport van het CBO wordt het verslag van een enquete gepubliceerd betreffende het aantal pijncentra en pijnbehandelingen in Nederland. Het bleek, dat een onverwacht groot aantal ziekenhuizen enigerlei voorziening had. Enerzijds duidt dit erop, hoezeer het probleem chronische pijn in aard en omvang is onderschat. Anderzijds blijkt, hoezeer er sprake is van een ongereguleerde wild groei, waarbij men zich terecht kan afvragen of de kwaliteit wel gelijke tred heeft gehouden met de toename van het aantal centra.

Tenslotte kan hopelijk in de toekomst geld worden terugverdiend door een terugdringen van ziekteverzuim en arbeidsongeschiktheid. De ervaring wijst uit, dat het niet zelden lukt om langdurig arbeidsongeschikten weer aan de slag te krijgen. Nader onderzoek zal nodig zijn om de kwantitatieve betekenis van deze factor vast te stellen. Het lijkt billijk om dan het eventuele terugverdieneffect ook gedeeltelijk aan de pijnbehandeling ten goede te laten komen. 
Dames en heren, ik nader het einde van dit betoog en het is mij een groot genoegen enkele woorden van dank uit te spreken, zoals de traditie dat wil.

Ik dank in de eerste plaats de faculteit der geneeskunde en de bestuurderen van de Nederlandse Stichting Pijnbestrijding voor het vertrouwen, dat $\mathrm{zij}$ in $\mathrm{mij}$ hebben gesteld. Het is een grote eer om deze leerstoel als eerste te mogen aanvaarden en ik zal mijn best doen Uw vertrouwen niet te beschamen.

Collega de Lange, beste Simon, ik heb grote bewondering voor de wijze waarop je mij in je afdeling hebt geintegreerd. Een perfecte samenwerking en een goede vriendschap waren het resultaat. Dat het lang zo moge blijven.

Collega Greep, beste Co, onze vriendschap gaat terug naar de zestiger jaren in Boston. Je hebt je zeer ingespannen bij het vestigen van deze leerstoel en getuigde daarbij van je verziende blik. Ik ben je daarvoor veel dank verschuldigd.

Van Kleef, Barendse en Dingemans, beste Maarten, Gerard en Wout, het leven in Maastricht is zonder jullie ondenkbaar. Jullie open, positieve houding bij mijn komst heeft een hechte band en een warme vriendschap geschapen. Samen verheugen wij ons bij het ontwaren van een nieuwe horizon en samen delen wij de tegenslagen waar goed klinisch onderzoek mee gepaard gaat. Zonder jullie had ik nooit kunnen weten waar ik een schroefje voor mijn bril moet halen en in welk etablissement de wetenschap zich zonder pijn laat wegspoelen.

Dr.Mehta, dear Mark, it is a great honour to have you here today. You taught me the first lessons in the treatment of pain over the fireplace in the Old Bakery. Your gentle, understanding approach to patients is the key that no double blind trial will ever 
detect. It is still today consciously on my mind in daily practice. Your true friendship is a treasure to me.

Professor Cosman, dear Eric, your help in developing this field has been indispensable. Our relationship has rapidly developed far beyond a professional one. I remember several of our lengthy telephone conversations in which $I$ have not been able to get you back to the business at hand. Please comply in the future and may our warm friendship flourish for many years to come.

Mevrouw Nieuwbuurt, lieve Monique, jou past wel een heel bijzonder woord van dank. Je houdt waarschijnlijk langere spreekuren dan ik, je schermt me af van wat ik niet wil horen en je schept orde in de traditionele chaos om mij heen - maar bovenal weet je feilloos wanneer je over de vrijwillige brandweer moet beginnen om mij op te beuren.

Lieve Fleur, lieve Ivo, jullie warmte en niet aflatende steun in moeilijke tijden gingen uit boven wat een vader van zijn kinderen mag verwachten. Ik zal er voor jullie zijn zolang het $\mathrm{mij}$ gegeven is.

En tenslotte dank ik U allen, waarde toehoorders, voor Uw belangstelling op deze voor de pijnbestrijding gedenkwaardige dag.

Ik heb gezegd. 
Referenties

Gibran, K.

The prophet (1923)

Alfred A.Knopf, N.Y.

Noordenbos,W.

Pain

Elsevier, Amsterdam (1959)

Melzack, R. and P.D.Wall

Pain mechanisms: a new theory

Science 150:971 (1965)

Kirschner, M.

Zur Elektrochirurgica

Arch.Klin.Chir., 167:761 (1931)

Sweet,W.H. and J.C.Wepsic

Controlled thermocoagulation of trigeminal ganglion and rootlets for differential destruction of pain fibres.

J.Neurosurg. 40:14 (1974)

Shealy, C.N.

Percutaneous radiofrequency denervation of spinal facets.

J.Neurosurg. 43:448-451 (1975)

Letcher,F.S. and S.Goldring

The effect of radiofrequency current and heat on peripheral nerve action potential in the cat.

J.Neurosurg. 29:42-47 (1969) 
Uematsu, S., G.B.Udrarhely, D.W.Benson and A.A.Siebens Percutaneous radiofrequency rhizotomy Surg. Neurol., 2:319-325 (1974)

Van Kleef,M.,F.Spaans, W.Dingemans, G.A.M.Barendse, E.Floor and M.E.Sluijter

Effects and side effects of a percutaneous thermal lesion of the dorsal root ganglion in patients with cervical pain syndrome. Pain 52:49-53 (1993)

Bogduk,N., W.Tynan and A.Wilson

The nerve supply to the human lumbar intervertebral discs.

J.Anat. 132:39-56 (1981)

Scott Peck, M.

People of the Lie

Simon and Schuster, N.Y.(1983) 